\title{
Sociedade Brasileira de Infectologia
}

\author{
Infectious Brazilian Society
}

\section{Senhor Editor:}

Arespeito da homenagem ao Dr. Ricardo Veronesi feita pelo Dr. Roberto Focaccia, muito bonita e enloqüente por parte de seu discípulo, no Boletim da Sociedade Brasileira de Infectologia (SBI) , Ano II, nº 6, abril/maio/junho de 2004, creio que tenha ele cometido uma injustiça com a Sociedade Brasileira de Medicina Tropical, cabendo uma correção. 0 Dr. Focaccia afirma que uma associação da Sociedade Brasileira de Infectologia com a Sociedade Brasileira de Medicina Tropical ( SBMT), foi buscada pelo Prof. Veronesi e rechaçada pela SBMT, a qual, por abraçar essencialmente apenas as endemias nacionais, teimosamente não abraria espaço à desamparada infectologia clínica.

Salvo engano, acredito que 0 caro Focaccia equivocou-se nessa consideração, uma vez que a SBMT tem uma visão ampliada na abordagem das Doenças Infecciosas, incluindo expressivamente a clínica e também todos os demais aspectos relacionados, razão pela qual abriu espaço, desde 0 início, a profissionais médicos e não médicos ligados a àrea. É esta a grande diferença entre a SBMT e a SBI a meu ver.

\section{Keyla Belízia Feldman Marzochi ${ }^{1}$}

1. Instituto de Pesquisa Evandro Chagas da Fundação Oswaldo Cruz, Rio de Janeiro, RJ.

Endereço para correspondência: Profa Keyla Belízia Feldman Marzochi. IPEC/FIOCRUZ. Av. Brasil 4365, Manguinhos, $21045-900$ Rio de Janeiro, RJ.

Tel: 21 3865-9595, Fax: 21 2590-9988

e-mail:keyla@ipec.fiocruz.br

Rebido para publicação em 29/10/2004

Aceito em 11/11/2004 